discussion of one preferred system. Fortunately, this does not happen to any such extent in other chapters; in fact, the chapter on gas analysis goes almost to the other extreme and presents the impor. tant aspects of the subject in a methodical and critical way.

Altogether, "Comprehensive Analytical Chemistry" has got away to a good start. There are bound to be a number of blemishes in such an ambitious work, but whether these will detract seriously from the value of the completed volumes is scarcely answerable at present. Undoubtedly this will become a standard reference work in analytical chemistry, but like all such extensive publishing projects, there is a considerable danger that, by the time the final volume comes from the press, the earlier volumes will be outdated. The rapid development of new methods and techniques in many branches of analytical chemistry tends to lessen the value of this encyclopædic type of text, except as a means of collecting together the available information at the time of writing. Too often publishing delays result in the presentation of much out-dated material, which the authors and editors are powerless to prevent.

This book has the dubious advantage over four other (to the reviewer's knowledge) similar projects in being first in the field. As such it is bound to come in for a good deal of comment not all of which will be friendly. Nevertheless, on the basis of this first volume, an appreciably high standard has been set for the complete work, and the appearance of the subsequent parts and volumes is awaited with considerable interest. Elsevier are to be congratulated on the fine printing and particularly the binding of this book which, as the series is completed, will add grace to the shelves of many libraries.

WiLliam I. Stephen

\section{ION EXCHANGE}

\section{lon Exchange Resins}

By Robert Kunin. Second edition. Pp. xiii +466. (New York: John Wiley and Sons, Inc.; London: Chapman and Hall, Ltd., 1958.) 88s. net.

\section{lon Exchange}

A Laboratory Manual. By Dr. J. E. Salmon and D. K. Hale. Pp. vii +136. (London: Butterworths Scientific Publications; New York: Academic Press, Inc., 1959.) 25s. ; 5 dollars.

W $\mathrm{HEN}$ the first edition of "Ion Exchange Resins" by Kunin and Myers appeared in 1950 it was only the second book on the subject in the English language. Since then, five more such books have appeared. However, only two of these have attempted general treatments of the subject and these two are brief monographs. There is still, therefore, plenty of scope within the covers of a single volume for a full length up-to-date account in English of ion exchange in all its aspects, fundamental and applied. This is what Dr. Kunin has attempted. $\mathrm{He}$ has certainly succeeded in considerable measure. The present work is both bigger and better than the first edition. Dr. Kunin's greatest successes are in the chapters on ion exchange application. He has done less well on the fundamental side.

Some of the faults of the first edition are still to be found here : a large number of diagrams, not always very clearly labelled or explained in the text; the occasional full account of older (sometimes obsolete) theories (particularly of ion exchange equilibria) with an inadequate amount of some of the recent work. In dealing with cation exchange kinetics on carboxylic exchangers Dr. Kunin repeats almost verbatim the account given in the first edition. The only reference he quotes in connexion with this topic is some work of Kunin and Barry in 1949. A few papers on this topic have been published since then but no mention is made of them. In particular, he ignores the important theory of Bauman, which many would consider to be at least as plausible as the theory of Kunin and Barry. However, the chapter on the synthesis of ion-exchange resins is a very great improvement on that in the earlier edition and there are excellent chapters on permselective membranes and catalysis with ion-exchange resins. In general, anyone reading the more fundamental parts of this book would be advised to refer also to other books (Kitchener or Griessbach) to check, supplement or correct the impressions gained. However, this book may be recommended as a useful reference work, particularly with regard to ion-exchange applications.

Dr. Salmon and Mr. Hale have broken completely new ground in their book. This splendid little book is an attempt (the first, so far as I know) to teach ion exchange to students by means of a carefully planned series of experiments. The first five chapters form a theoretical introduction to the remainder of the book, which contains the experiments. The discus sions of the experiments form a particular feature of the book and they are both clear and stimulating. The authors' statement (p. 116) that "The regeneration of a mixed-bed column is not readily achieved with small laboratory columns" may not command universal assent, and the consequent omission of any account of such regeneration procedures is open to eriticism. Indeed, many workers would probably prefer a straightforward mixed-bed column for de-ionization to the three-stage procedure described by the authors. However, these are comparatively minor points which later editions may remedy. This book deserves every success, as it should be useful not only to students but also to all laboratory workers who have anything to do with the practical side of ion exchange.

D. ReichenberG

\section{GEOCHEMICAL RESEARCH IN THE UNITED STATES}

\section{Researches in Geochemistry}

Edited by Philip H. Abelson. Pp. $x+511$. (Now York: John Wiley and Sons, Ine.; London : Chapman and Hall, Ltd., 1959.) 88s, net.

7 HIS book, edited by the Director of the Geophysical Laboratory, Washington, is the outcome of a seminar series in geochemistry organized by the Geophysical Laboratory and held there, and at the Johns Hopkins University, during the academic year 1957-58.

It gives a valusble conspectus of current goochemical research in the United States, and the wide range of topics covered is best indicated by listing the titles of the contributions (authors' names in brackets): sedimentation on the ocean floor (G. O.S. Arrhenius), pp. 1-24; rates of geochemical reactions at low temperatures and pressures (R. M. (Garrels), 